\title{
O MUSEU COMO ESPAÇO DE CONSTITUIÇÃO DA FORMAÇÃO DOCENTE EM CIÊNCIAS E BIOLOGIA
}

\section{THE MUSEUM LIKES A SPACE OF CONSTITUTION OF TEACHER'S FORMATION OF SCIENCE AND BIOLOGY}

\author{
SOUSA, Carlos Erick Brito de \\ cazeck8@yahoo.com.br \\ Universidade Federal do Maranhão (UFMA) \\ CARVALHO NETA, Raimunda Nonata Fortes \\ raimundafortes@yahoo.com.br \\ Universidade Estadual do Maranhão (UEMA)
}

\begin{abstract}
RESUMO Os museus constituem espaços privilegiados para a construção do conhecimento e formação docente. Nesta perspectiva, este estudo visou investigar a divulgação de conhecimentos em um museu de ciência e sua apropriação por licenciandos em Ciências Biológicas, enquanto leitores de um acervo científico que também apresenta características estéticas. Realizamos pesquisa bibliográfica, documental e de campo no Centro de Pesquisa de História Natural e Arqueologia do Maranhão (CPHNAMA). Observamos que, em relação aos níveis de compreensão estética, a maioria dos estudantes comportou-se como leitores narrativos, seguidos por leitores classificativos e re-criativos. Quanto à importância dos museus de ciências para a formação docente, observou-se que para a maioria dos estudantes: serve para aprender mais sobre a História Evolutiva dos seres vivos; as visitas complementam o que é aprendido na graduação; e enriquecem os conhecimentos desenvolvidos em sala de aula. Constatamos, no que diz respeito à formação docente, que os museus de ciência possibilitam: aprimorar os conhecimentos biológicos em atividades que valorizam a divulgação e a alfabetização científica; melhorias no processo de ensino-aprendizagem nas universidades e nas relações entre estas instituições e os museus; maior reflexão sobre a importância destes tipos de atividades para as práticas docentes; oportunidades de utilização desses espaços como recursos complementares aos trabalhos desenvolvidos no âmbito escolar.
\end{abstract}

PALAVRAS-CHAVE: Ensino de Ciências e Biologia. Formação de professores. Museu de Ciência.

ABSTRACT The museums are privileged space to the construction of knowledge and teacher's formation. In this perspective, the study aims to investigate the knowledge divulgation in a science museum and its appropriation by university students of Biology, while readers of a scientific heap that also presents aesthetic characteristics. We realize bibliographic and documental, and field research in Centro de Pesquisa de História Natural e Arqueologia do Maranhão (CPHNAMA). We observe that in relation to the aesthetic comprehension levels, the majority of the 
students behave like narrative readers, followed by classifiers and re-creative. To the importance of museums for teacher's formation, was observed that to the majority of the students: it serves to learn more about the Evolution History for living being; the visits complement what they learn in graduation; and enrich the knowledge in classroom. We find, in relation to teacher's formation, that the science museums enable: increase biological knowledge in activities that value the scientific disclosure and literacy; improvements in the university teaching and learning process and the relations between these institutions and the museums; more reflections about the importance of these kinds of activities to the teacher's practices; opportunities by utilization of these spaces like complementary resources to the work developed at school environment.

KEYWORDS: Science Museum. Teacher's Formation. Science and Biology Teaching.

\section{INTRODUÇÃO}

As questões referentes ao nosso cenário educativo despertam bastante interesse pela formação que possuímos, enquanto pesquisadores da área da Educação e como professores, num contexto em que despontam carências no que diz respeito a uma formação de qualidade, que sirva para a constituição de cidadãos, no sentido estrito do termo. Chama-nos atenção, neste panorama, a formação de professores na realidade que vivenciamos - no caso investigado, egressos da Licenciatura em Ciências Biológicas da Universidade Estadual do Maranhão (UEMA) - cujos reflexos serão sentidos no âmbito da Educação Básica, especialmente no ensino público, em que poderão atuar.

Vivemos um mundo de rápidas mudanças tecnológicas, cujos efeitos se traduzem em constantes transformações sociais, as quais também são sentidas na escola, visto que os jovens acompanham estas modificações, onde ciência e tecnologia encontram-se cada vez mais imbricadas com as questões sociais, culturais, políticas e econômicas. Concordamos com Delizoicov, Angotti e Pernambuco (2009), quando discutem que estas novas configurações não podem passar inertes ao contexto escolar e aos programas de formação de professores, assim, devemos estar atentos para a necessidade da constituição de uma cultura científica nesses espaços, onde essas discussões estejam presentes.

Uma das estratégias apontadas para este contato é a oportunidade de inserir materiais e atividades de divulgação científica (jornais, revistas, Internet, histórias 
em quadrinhos, museus, laboratórios e centros de ciência, parques zoobotânicos, exposições, feiras e clubes de ciências, fixos ou itinerantes), os quais "[...] não podem permanecer ausentes ou desvinculados do processo de ensino/aprendizagem, mas devem fazer parte dele de forma planejada, sistemática e articulada" (DELIZOICOV; ANGOTTI; PERNAMBUCO, 2009, p. 37). Estas estratégias, que se caracterizam pela possibilidade de um aprendizado não-formal, se realizadas da maneira proposta por estes autores, podem oferecer contribuições ao enriquecimento dos contextos formais de aprendizagem.

Tendo em vista esta perspectiva, situamos esta pesquisa na investigação das práticas pedagógicas realizadas em um museu de ciência para divulgação científica dos conhecimentos biológicos e as apropriações destes mesmos conhecimentos por licenciandos em Ciências Biológicas, em virtude das experiências vivenciadas neste ambiente e da importância que concedem a esta possibilidade de aprendizagem, em relação à sua formação como professores.

Neste contexto, despontam como objetivos deste trabalho: identificar as estratégias de divulgação de conhecimentos biológicos realizadas em museu de ciência e as apropriações de conhecimentos pelos licenciandos, em relação aos níveis de compreensão estética; discutir a importância dos museus de ciência para a divulgação científica, aprendizado não-formal dos conhecimentos biológicos e enquanto espaço de constituição docente.

\section{OS SUJEITOS DA PESQUISA E OS CONTEXTOS DE INVESTIGAÇÃO}

Para a consecução deste trabalho, realizamos pesquisa bibliográfica e documental, e pesquisa de campo em um museu de História Natural. Assim como Megid Neto e Fahl (2005), consideramos adequado para este tipo de pesquisa uma abordagem qualitativa, portanto, os dados foram gerados a partir da combinação de diferentes estratégias e instrumentos de investigação (observações in loco, conversas informais, questionários semiestruturados). Nesse sentido, tais estratégias de pesquisa corroboraram para análise da visita de licenciandos em Ciências Biológicas à Sala Expositiva de Paleontologia do Centro de Pesquisa de 
História Natural e Arqueologia do Maranhão (CPHNAMA) ${ }^{1}$, onde podem ser encontrados especialmente materiais fossilíferos do Cretáceo, coletados em diversos municípios maranhenses.

Entre os sujeitos investigados na pesquisa estavam 12 licenciandos em Ciências Biológicas da UEMA, do $5^{\circ}$ semestre, que cursavam a disciplina de Zoologia dos Vertebrados, cujas idades variavam entre 20 e 24 anos, sendo somente dois fora dessa faixa etária, com 34 e 53 anos respectivamente; apenas quatro eram do sexo masculino. A visitação ao CPHNAMA, realizada no segundo semestre de 2009, fez parte do contexto das atividades realizadas na disciplina, onde após estudarem os fósseis de vertebrados em sala de aula, partiram para o museu, a fim de ressignificar os conhecimentos biológicos a respeito do acervo fóssil maranhense, sob o comando de monitores da instituição.

Em virtude da importância dos monitores para a condução das visitas ao ambiente museal, os quatro monitores do CPHNAMA também foram incluídos entre os sujeitos da pesquisa, no intuito de investigar as diferentes estratégias de divulgação de conhecimentos, enfatizando a visita realizada pelos universitários da área de Biologia. Os monitores, dois do sexo feminino e dois do sexo masculino, possuíam de 22 a 25 anos, dois eram graduados (Geografia e Biologia) e dois ainda cursavam a Universidade ( $6^{\circ}$ semestre de Geografia e $8^{\circ}$ semestre de Letras).

O questionário aplicado aos monitores do CPHNAMA buscava investigar como avaliavam o seu trabalho no museu, a formação que possuíam e se acreditavam que os conhecimentos advindos da graduação contribuíam para a atuação como monitores, e onde buscavam fontes de conhecimentos para aprimorar o seu trabalho. Estes sujeitos foram indagados também sobre os tipos de visitas que costumavam guiar e os tipos de público que costumavam receber, e o que mais colaborava para facilitar as explicações e promover o entendimento sobre os assuntos apresentados durante a visita. Por fim, eram questionados a respeito das exigências que eles consideravam necessárias para receber um grupo de estudantes de Ciências Biológicas. Acompanhamos a visita dos licenciandos em

\footnotetext{
${ }^{1}$ Foi oficialmente estruturado a partir da assinatura do Decreto 17.643 , que viabilizou a sua criação em 27 de março de 2002, e está situado em um sobrado colonial na Rua do Giz, n. 59, Centro Histórico de São Luís - MA. Entre seus principais objetivos, estão o planejamento e desenvolvimento de pesquisa e divulgação nas áreas de Arqueologia e Paleontologia no cenário maranhense, enfatizando o resgate, a preservação e a valorização do acervo patrimonial.
} 
Ciências Biológicas, guiada por um dos monitores, a fim de observarmos como se processava esse trabalho de mediação e divulgação dos conhecimentos biológicos associados ao acervo do museu, para o grupo de professores em formação.

Para analisarmos as experiências, concepções e discursos dos estudantes, aplicamos dois questionários. O primeiro foi respondido antes da visita e o outro após o conhecimento do acervo e interações com o mediador do museu. A fim de conhecermos melhor o grupo de licenciandos e suas perspectivas quanto à formação docente e as motivações que os levaram a optar pela licenciatura, inserimos perguntas a respeito destes aspectos no primeiro questionário. Este mesmo instrumento também contemplava questões relativas ao conhecimento dos estudantes sobre museus e museus de ciência. Desse modo, foi questionado: se já haviam tido a oportunidade de ir a algum museu; que museus foram visitados; como havia sido a experiência de vivenciar um dia no museu; se conheciam algum museu de ciência localizado em São Luís - MA e se já haviam visitado este espaço. Os licenciandos também eram indagados, nesse primeiro instrumento, sobre a importância que os museus de ciência poderiam representar para a formação de professores de Ciências e Biologia, e que expectativas possuíam em relação à visita que iriam realizar.

O segundo questionário, aplicado após a visita ao CPHNAMA, questionava: o que a visita havia representado para os estudantes; o que conseguiram aprender; o que pareceu mais significativo durante a visita; o que conseguiam recordar do acervo e das explicações que haviam sido fornecidas pelo mediador. A última questão indagava se, após a visita, eles consideravam o museu de ciência um espaço importante para a formação de professores de Ciências e Biologia, adicionando suas justificativas. Como as questões eram abertas e as respostas foram variadas, para todos os questionários, os critérios de análise das mesmas não foram decididos a priori. A partir de elementos emergentes das respostas obtidas nos questionários, categorias que se aproximavam ou se diferenciavam, foram sendo estabelecidas novas classificações e reorganização das mesmas para análise do material coletado durante a pesquisa.

Destacamos que todos os participantes (maiores de idade) receberam Carta contendo explicações para a obtenção do Termo de Consentimento Livre e 
Esclarecido, onde ficaram claros: os objetivos da pesquisa; o caráter voluntário da participação, não determinando qualquer risco ou desconforto; a garantia de acesso a informações ou retirada de consentimento em qualquer etapa do estudo; a manutenção de sigilo em relação às suas identidades; e ainda que os dados coletados seriam utilizados apenas para esta pesquisa. Declaramos também seguir o cumprimento das normas vigentes na Resolução Nº 196/96 do Conselho Nacional de Saúde/Ministério da Saúde e complementares. Para a manutenção de sigilo sobre a identidade dos sujeitos que aceitaram participar da pesquisa, foram adotados os seguintes códigos, específicos para cada grupo: "M" para os monitores e "B" para os licenciandos em Biologia, sendo que, para cada indivíduo, adotamos aleatoriamente um número para diferenciar os sujeitos da pesquisa (M1 a M4 e B1 a B12).

\section{A VISITA ÀS PESQUISAS EM AMBIENTE MUSEAL}

Realizar uma pesquisa sobre a dimensão educativa das atividades realizadas em museus requer uma imersão no desenvolvimento destes ambientes em nossa realidade, percebendo as tendências pedagógicas que subjazem suas diferentes fases históricas, nos contextos em que emergiram. Tais transformações nos indicam os percursos assumidos até as configurações com as quais nos deparamos hoje, no que diz respeito à disposição dos aparatos, coleções e demais peças museológicas, tipos de exposições e estratégias de comunicação utilizadas para os diferentes públicos. Nesse sentido, procedemos a uma breve visitação a pesquisas que buscam resgatar estes momentos.

A história dos museus de ciência remonta ao século XVII. Cazelli et al. (1999) discorrem sobre o papel do "gabinete de curiosidades", que seria uma espécie de ancestral destes espaços, onde eram apresentados, de modo desorganizado, objetos como quadros, moedas e equipamentos científicos, além de animais empalhados, fósseis etc. Algum tempo depois, as coleções passaram a ser disponibilizadas de maneira mais estruturada, servindo como suportes de demonstração para estudo e difusão da ciência; a partir daí, os museus de História Natural começaram a tomar forma. 
No Brasil, o crescimento da 'preocupação' com o campo da Educação teve maior amplitude após a chegada da Coroa Portuguesa no início do século XIX. Assim, em 1818, foi fundado o Museu Nacional, cujos objetivos eram: colecionar riquezas do Brasil, propagar os conhecimentos e incentivar os estudos das Ciências Naturais. Na década de 70 do século XIX, com a implantação dos "Cursos Públicos do Museu", foi instituída uma proposta com o intuito de favorecer a instância educativa, cuja finalidade, conforme Massarani e Moreira (2002), seria instruir o povo, mais precisamente "inocular nos jovens o gosto pelas pesquisas científicas". Os cursos eram ministrados por pesquisadores do próprio museu nas diferentes especialidades, no entanto, estas atividades se desgastaram, declinando após dez anos.

Outro momento considerado de destaque nesse mesmo período foi a iniciativa de Emilio Goeldi no comando do Museu Paraense, que se destinava ao "estudo, desenvolvimento e vulgarização da História Natural e Etnologia". Também houve, nesse pioneirismo, a criação de um momento onde a população tivesse acesso aos conhecimentos científicos, com as palestras, geralmente sobre temas relacionados à Amazônia, realizadas pela "Sociedade Zeladora do Museu Paraense". Essas oportunidades de ampliação do acesso às informações científicas acompanhavam um verdadeiro "surto" de atividades de divulgação científica, em várias regiões do país (MASSARANI; MOREIRA, 2002).

Os museus de História Natural foram sendo implantados em outros estados brasileiros, seguindo os mesmos preceitos de servir para preservação de coleções, espaços de estudo e divulgação científica, tendo, entretanto, um "comportamento mais tímido", em relação à proposição de atividades de forte apelo público. Cabe destacar, nesta etapa, a perspectiva levantada por Alves (2007), que ressalta o fato de os museus terem sido criados por setores dirigentes, e, portanto, sua estrutura, por vezes, objetivava manter a ideologia do status quo. Assim, o acesso a esses espaços era restrito, prevalecendo argumentos de que a população não se interessava pelos acervos histórico-culturais e não saberia como se comportar nesses locais; os museus de ciência não passaram incólumes a este processo. A pesquisadora alega ainda que tal prerrogativa pode ter corroborado para o equívoco a respeito dos museus, vistos, por vezes, como estáticos e sem dinamicidade. 
Studart (2005) mostra que o campo da Psicologia Educacional trouxe novas discussões sobre o desenvolvimento cognitivo de crianças e adolescentes, repercutindo nas instâncias educativas que propunham atividades para estes públicos; este movimento de transformação do cenário educacional incidiu na popularização dos museus. Dessa maneira, no final da década de 1960, surgiram centros de ciência e centros de descoberta - estabelecimentos que se caracterizavam pelo incentivo à criação de ambientes de aprendizagem ativa, estimulando a criatividade e o comportamento exploratório. Acompanhando essas tendências internacionais, os museus e centros de ciências se implantaram com maior ênfase no Brasil no início dos anos 1980, ampliando-se na década seguinte (MASSARANI; MOREIRA, 2002; MARANDINO, 2005), quando cresceu a importância, em termos de pesquisa, das áreas de divulgação científica e educação não-formal.

Marandino (2005) expõe a constituição de um novo paradigma para as exposições em museus de ciência com as novas tecnologias e inovações em Museologia, Comunicação e Educação, que impõem posturas diferenciadas na tentativa de acompanhá-las e atrair o público interessado nos assuntos científicos. Contudo, a autora percebe que, no Brasil, ainda são poucos os que vêm incorporando as recentes tendências em museologia científica.

Jacobucci et al. (2007) mostram que, mesmo não existindo um levantamento do número de professores que visitam os núcleos de divulgação científica do país, entre estes os museus de ciência, é de domínio comum que eles frequentam esses espaços, todavia, são escassas as pesquisas que buscam investigar o que esses professores procuram e como esses espaços contribuem à sua formação profissional.

Ovigli, Freitas e Caluzi (2010) destacam que a produção científica da área tem crescido, todavia, observam relativa escassez de estudos que investiguem os papéis desempenhados pelos mediadores nos museus e que considerem os museus de ciência como espaços educativos, analisando as experiências de aprendizagem nesses locais.

Valente (2014) argumenta que a história dos museus de ciência no Brasil é recente, assim como a produção de pesquisas nesta área, que foram impulsionadas 
especialmente nas últimas décadas. Nesse contexto, os museus passam a ter maior relevância como objetos de estudo, sendo analisados a partir de diferentes prismas, principalmente por disciplinas das Ciências Sociais e Humanas, cuja tendência se reflete na implantação de cursos de pós-graduação na área de Museologia e no surgimento de publicações que têm contribuído para reflexões acadêmicas deste campo. Para a pesquisadora, este maior interesse se sustenta porque "[...] os museus de ciências, como instituições renovadas, são considerados espaços privilegiados de divulgação científica e de preservação do patrimônio da ciência e tecnologia" (VALENTE, 2014, p. 48-49).

Diante destas considerações e no intuito de contribuir para o incremento desta área, buscamos investigar como se dão as relações entre os museus de ciência e a sua importância para a formação docente na área de Biologia. Desta forma, pretendemos observar de que maneiras o museu de ciências é ou pode ser inserido como espaço privilegiado para a constituição de professores, tendo em vista a associação entre espaços formais e não formais de educação para a ampliação da divulgação científica dos conhecimentos biológicos. Esta aproximação também poderá resultar em melhorias no processo de ensino-aprendizagem de Biologia nas universidades e no trabalho dos licenciandos, futuros professores das disciplinas escolares Ciências e Biologia.

\section{A DIVULGAÇÃO DOS CONHECIMENTOS BIOLÓGICOS NA EXPOSIÇÃO DE PALEONTOLOGIA DO CPHNAMA}

\subsection{CONDUÇÃO DAS VISITAS E PERFIL DOS MONITORES DO CPHNAMA}

Silva et al. (2007) destacam que os museus e centros de ciência possibilitam uma oportunidade de formação de monitores para a condução de visitas às salas expositivas, os quais são geralmente alunos de cursos com formação científica na área referente ao acervo. Marandino e Martins (2005, p. 79) complementam este ponto, ressaltando que muitos museus de ciência estão ligados a universidades, funcionando com uma experiência eficaz para a formação de jovens universitários e para melhoria do atendimento oferecido por estas instituições. Assim, para as 
autoras, "[...] a monitoria passa a ser um espaço de vivência e de experimentação de formas de traduzir as informações científicas para diferentes públicos".

O CPHNAMA está ligado a Grupos de Pesquisas em Paleontologia e Arqueologia da Universidade Federal do Maranhão, e, assim como outros museus de ciência, possibilita essa contribuição à formação continuada de seus monitores, como atesta M2: "Sinto-me mais próximo de uma parte importante da nossa história e posso ajudar outras pessoas a entender essa história". O perfil de formação (curso de graduação, concluído ou em andamento) de três monitores (Biologia e Geografia) ajuda na preparação para os trabalhos realizados no museu: "Com o embasamento teórico no momento da explanação e das perguntas" (M1); "Pelo conhecimento na área" (M3); "Na didática usada para guiar os visitantes e em conhecimentos específicos, como Geologia" (M2). Apenas M4, estudante de Letras, acredita que sua formação não colabora muito para a realização das atividades no museu.

Gomes e Cazelli (2014) também investigaram a formação dos mediadores de museus de ciência, sendo boa parte destes estudantes das licenciaturas relacionadas à área de atuação dos museus. As autoras observaram, assim como no presente estudo, que grande parte dos monitores acredita que a formação acadêmica que possuem contribui para a realização de suas atividades nos museus. No que diz respeito ao caso de M4 (monitora que aceitou participar do presente estudo), as pesquisadoras encontraram algumas situações similares em sua investigação, em que alguns monitores, geralmente de áreas mais distanciadas do campo de atuação dos museus, reconheciam poucas contribuições de sua formação para os trabalhos a serem desenvolvidos nesses espaços.

Como resultados de seu trabalho, Gomes e Cazelli (2014) encontraram dois principais tipos de fatores, em termos das contribuições da formação acadêmica para a atuação nos museus de ciência: 1. os mediadores de museus oriundos dos cursos de licenciatura ressaltaram as contribuições relacionadas aos conhecimentos e práticas na área de Educação; 2. os mediadores que possuíam formação acadêmica nas áreas afins à atuação dos museus destacaram as contribuições relativas aos conteúdos das ciências de referência abordados nos museus. De acordo com essas proposições, as respostas de M1, M2 e M3 (investigados pelo 
presente estudo) se aproximariam das características apontadas pelas pesquisadoras.

Os monitores costumam buscar em fontes variadas as informações que ajudam a melhorar seu trabalho de divulgação de conhecimentos: "materiais de divulgação confeccionados pela equipe do museu"; "reuniões e debates com a equipe de monitores e responsáveis pelo espaço"; "livros de História Natural e Paleontologia" (M2, M3 e M4); "revistas científicas (acadêmicas)" - M1, M2 e M3, e "de divulgação científica" - M1 e M3; "filmes didáticos sobre a temática" (M1, M3 e M4). M1 cita ainda os cursos de formação fornecidos pelo próprio museu; já M3 destaca a participação em Grupos de Pesquisa sobre História Natural e Paleontologia, os filmes comerciais (geralmente ficcionais sobre o tema) e as aulas do curso de Ciências Biológicas (já concluído); e M2 acrescenta a leitura de livros paradidáticos relacionados ao tema.

Em estudo realizado por Schwenk e Marteleto (2011), foram encontrados resultados similares ao presente trabalho, no que diz respeito à busca por fontes de informações pelos monitores de um museu de ciência. Os mediadores entrevistados pelas autoras relataram: utilizar pesquisas em sites da área na Internet e consultas a livros e outros suportes de informação próprios ou do acervo do museu e de universidades; participar de capacitações coordenadas pelo museu onde atuam; realizar troca de conhecimentos e compartilhamento de informações entre os colegas da equipe. Durante as entrevistas, os monitores revelaram recorrer a colegas mais experientes ou de formações diferentes para esclarecer dúvidas e ampliar seus conhecimentos sobre os assuntos abordados durante as visitas ao museu, asseverando a importância da comunicação entre os membros da equipe, de caráter multidisciplinar e com diferentes níveis de formação (de graduandos a pós-graduados).

\subsection{PRÁticAs PEDAGÓgICAS E ESTRATÉGIAS DE DIVULGAÇÃO DOS CONHECIMENTOS BIOLÓGICOS}

$\mathrm{Na}$ visita realizada pelos estudantes de Ciências Biológicas ao CPHNAMA, M3, biólogo, que os conduziu, fez uma mescla de visita guiada e discussão dirigida, 
seguindo um percurso que revela os achados fósseis, especialmente de flora e fauna, conforme a ordem cronológica de seu surgimento, numa ida e volta constante, dos fósseis e vestígios dispostos na Sala de Exposição aos aparatos e dioramas que os representam em suas interações ecológicas; sendo isto asseverado pelo fim do percurso em um painel que explica a "Linha do Tempo". Os estudantes geralmente questionavam algo sobre as representações, maquetes, tamanho, cor, forma e estrutura dos fósseis e eram respondidos no mesmo momento. Também eram constantes as indagações do monitor: "Já ouviram falar?", "Vocês conhecem?", "Vocês lembram?".

Uma faceta aproveitada pela comunicação expositiva em museus é o diorama - recurso cenográfico incorporado pelos museus de ciência para explicar os princípios científicos e tecnológicos e/ou tentar reproduzir o contexto de origem de um grupo de animais ou da utilização de determinados objetos. Nessa cenografia, cabe o uso de objetos, materiais fósseis, suas representações ou tentativas de sua reconstituição - patrimônios do próprio acervo do museu com outros elementos que complementem essa perspectiva. A disposição dos dioramas no CPHNAMA facilita a visualização das interações entre os fósseis apresentados, visto que acompanha a ordem de sucessão apresentada, sendo bastante explorados pelos guias, fato reforçado pelas posições de M3 e M4, que utilizam esses ambientes cenográficos para incitar a imaginação e organizar a movimentação do grupo em um roteiro predeterminado.

Para os monitores, colaboram para facilitar as explicações e o entendimento dos assuntos apresentados na visita: "a participação dos visitantes fazendo questionamentos ou respondendo às inquirições propostas"; "os fósseis e outros vestígios que comprovem a existência dos seres vivos abordados nas explicações" (M2, M3 e M4); "interesse e encanto dos visitantes pelas temáticas abordadas" (M1, M3 e M4); "manter a ordem preestabelecida para guiar a visita até o final, sem grandes alterações" (M2, M3 e M4); "as legendas que acompanham as peças do acervo" (M2 e M3). Quanto ao nível de conhecimento dos visitantes do assunto: M1 prefere os que possuem mais aprofundamento no tema; para M3, as pessoas que possuem informações mais superficiais sobre o assunto também fazem parte de 
seus visitantes preferenciais. Apenas M3 considera interessante que os visitantes realizem passeios informais livres ao redor do acervo, antes da visita guiada.

O público que costuma visitar o CPHNAMA é constituído de estudantes da Educação Básica e do Ensino Superior, geralmente trazidos por seus professores como parte de atividades escolares, e por turistas, principalmente por estar localizado no Centro Histórico de São Luís - MA, onde há grande fluxo de pessoas de outros estados brasileiros e de outros países que vêm conhecer o patrimônio histórico-cultural da cidade. Os monitores revelam as motivações e objetivos de cada grupo de visitantes:

"Os grupos escolares vêm focados em adquirir ou complementar conhecimentos, como ponte entre o que foi visto em sala e o que veem aqui, então são geralmente mais concentrados e querem saber tudo. Os turistas são, na maior parte, menos curiosos. A maioria entra, dá uma rápida olhada e vai embora" (M4).

"[...] a principal diferença é que os grupos de estudantes já vêm orientados para aquela temática e os turistas vêm ao museu para conhecer o novo, sem preocupações quanto ao relatório que deverão apresentar no final da visita ao seu professor, como no caso dos estudantes" (M1).

Este ponto destacado por M1 foi algo que pudemos observar durante 0 acompanhamento da visita, onde preocupados com esta sistematização de informações para a confecção de relatórios, os estudantes pareciam prestar mais atenção, em certos momentos, às informações disponibilizadas nas fichas contendo explicações do que na fala do monitor, ou então, permaneciam por mais algum tempo na área onde aconteceu a explicação anterior, concluindo alguma anotação, enquanto o grupo já estava sendo atraído para novos esclarecimentos sobre outras peças do acervo. Concordamos com Marandino e Martins (2005) quando chamam atenção para o fato de que nem sempre os visitantes sentem vontade de realizar visitas monitoradas e os museus devem estar preparados para essa possibilidade, para que mesmo sem a presença de um monitor, as informações sejam compreendidas.

No que diz respeito à recepção de um grupo de estudantes de Ciências Biológicas, os monitores acreditam que algumas exigências se fazem necessárias para a sua preparação no intuito de guiar essa visita: para $M 3$, é importante ter conhecimento da área, estando pronto para estabelecer as relações existentes entre os grupos extintos e os grupos atuais, destacando suas similaridades e diferenças; 
já M1 considera necessário ter uma "preparação teórica para a explanação dos conteúdos propostos na mostra". De acordo com M2, a visita dos estudantes de Biologia pode se tornar interessante quando o monitor busca "esclarecer o máximo sobre as peças expostas, provocar um debate entre os estudantes para testar seus conhecimentos, o que pode depender do período em que a turma se encontra".

\section{LICENCIANDOS EM CIÊNCIAS BIOLÓGICAS E SUAS RELAÇÕES COM O AMBIENTE MUSEAL}

\subsection{AS EXPERIÊNCIAS DE ENSINO-APRENDIZAGEM DOS LICENCIANDOS EM AMBIENTE MUSEAL}

Dentre os 12 licenciandos, apenas dois (B2 e B10) escolheram a área de Biologia em função da Licenciatura. Após o contato com os conhecimentos pedagógicos durante as disciplinas do curso, apenas quatro não pretendem ser professores: B6 e B7 que preferem a área da pesquisa; B8 que acredita não ter mais idade para ser professora de Ciências/Biologia; e B9, que apesar de declarar sua paixão pela Biologia, não se identifica com a atividade docente. Entre os que pretendem seguir a carreira de professor, as opiniões envolvem: "a identificação com a área e gosto pela profissão" (B1 e B2); "o interesse pelo estudo, a partilha de conhecimentos e fazer com que outros possam gostar de Biologia" (B3 e B12); "ter o privilégio de formar cidadãos" (B10); "maiores oportunidades de trabalho" (B4). Para B5, trata-se de "[...] uma área abrangente, onde se pode explorar e conectar conteúdos diversos". E B11, após o contato com o curso, já se sente "capacitado e bem à vontade para transmitir os conhecimentos adquiridos".

No que concerne à prática de visitação a museus por parte dos licenciandos, somente B4, B7 e B12 nunca haviam ido a um museu antes da atividade realizada com a turma de Ciências Biológicas. Dos nove restantes, cinco já haviam visitado um museu por iniciativa própria e cinco em atividade escolar, de faculdade ou similar, já que B11 se encaixava nas duas opções. Apesar do relativo crescimento desse importante espaço de preservação de nosso patrimônio e de divulgação de conhecimentos, Massarani e Moreira (2002, p. 61) revelam que "[...] um número 
muito pequeno de brasileiros, cerca de 1,5 milhão (menos de $1 \%$ da população) visitam algum centro ou museu desse tipo a cada ano". Acrescenta-se à constatação, segundo estes autores, a oferta limitada de exposições, seu pequeno porte, as condições econômicas e educacionais, além de uma frágil tradição cultural nesse tipo de programa educativo.

Gomes e Cazelli (2014) complementam esta discussão, ao indicarem que, apesar de representarem espaços complementares interessantes para a formação docente, ainda existe certo distanciamento entre os museus e as universidades, limitando o estabelecimento de parcerias e o incremento destas atividades no âmbito da graduação. As autoras acrescentam que há perdas consideráveis na ausência destas atividades, uma vez que os museus são espaços não formais de educação de grande relevância para a formação inicial e continuada de professores, tendo em vista o aprimoramento das práticas pedagógicas do professor e a possibilidade de utilizar esses espaços como recurso complementar aos trabalhos a serem desenvolvidos no contexto escolar.

[...] O museu desenvolve ações científicas, culturais e educativas, tornandose, assim, um espaço privilegiado para o envolvimento dos cursos de formação docente, reforçando o componente educacional que a referida instituição vem assumindo na atualidade (OVIGLI, 2011, p. 147).

Em relação ao conhecimento de algum museu de ciência localizado em São Luís - MA, cinco responderam não conhecer (B4, B7, B10, B11 e B12); dos que disseram conhecer, apenas B3 não respondeu qual museu conhecia. Foram citados como museus de ciência: CPHNAMA (4 licenciandos); B6 respondeu "Casa do Maranhão"; e, para B8, todos os museus que ela havia mencionado ("Museu de Arte Sacra, Museu de Artes Visuais, Casa do Maranhão, CPHNAMA, Museu do Negro") não deixavam de ser de ciência. Tal verificação demonstra que não estão totalmente claras, para os estudantes de Biologia, as especificidades que caracterizam um museu de ciência. Os sete estudantes que afirmaram conhecer um museu de ciência, consideraram a atividade como interessante.

Antes da visita ao CPHNAMA, os estudantes reuniam uma série de expectativas que os motivavam a vivenciarem a ida ao museu: "aprender mais sobre Biologia" (16\%); "observar com calma a recriação de cenários onde os seres vivos se desenvolveram" (14\%); "aprender algo que poderia ser ensinado em sala de aula" 
(14\%); "participar de uma atividade interessante" (13\%); "conhecer novidades sobre o nosso passado" (12\%); "ver partes e representações de dinossauros e outros animais, bem como de vegetais de eras remotas" (12\%); "saber classificar corretamente os períodos históricos dos seres vivos que habitaram nosso planeta" (10\%); "fazer o máximo de questionamentos que pudessem ao monitor, para sair do museu sem nenhuma dúvida" (9\%). A expectativa de B1, B10 e B12 envolvia a realização de um sonho antigo: "ter um maior aprofundamento em algo que só viam nos livros". Como nos mostra a literatura, e isto pode ser observado em algumas práticas, a visita ao museu não precisa ser uma atividade monótona, estática, e é nessa perspectiva que B10 e B11 almejavam um dia animado e de grande aprendizado.

Após a visita, tentamos perceber como os licenciandos passaram a enxergar a importância desta atividade, diante de suas ideias prévias e da materialização dos processos de ensino-aprendizagem dos conhecimentos biológicos no museu de História Natural. As respostas dos licenciandos em Ciências Biológicas trataram: "da oportunidade de ter uma aula diferente, dinâmica, lúdica, animada"; "da possibilidade de incrementar os conhecimentos em Biologia, a partir das informações científicas disponibilizadas pelo museu de ciência"; "de fomentar suas práticas enquanto (futuros) professores, melhorando seu trabalho docente".

De acordo com Coutinho-Silva et al. (2005, p. 25), a aproximação entre centros de divulgação científica e universidades, tendo em vista o ensino de ciências em espaços não-formais traz vantagens a todos os envolvidos. "[...] Os graduandos (em especial os de licenciatura), além de receberem uma grande gama de conteúdo teórico-experimental [...] vivenciam um processo de ensino-aprendizagem que se dá de forma dinâmica e lúdica". Nesse sentido, a vivência no museu de ciência pode se apresentar como uma rica experiência de aprimoramento dos conhecimentos biológicos, onde a partir do contato com o acervo, os aprendizados não-formais podem repercutir na atuação do professor nos espaços em que atua, especialmente no ambiente escolar.

\subsection{APROPRIAÇÕES DE CONHECIMENTOS E NÍVEIS DE COMPREENSÃO ESTÉTICA EM MUSEUS DE CIÊNCIA}


Carvalho Neta (2005) traz um fator importante a ser considerado no estudo de ambientes museais, quando aborda a necessidade de o professor identificar o nível de compreensão estética de seus alunos, contribuindo para formar o olhar dos educandos. Esta pesquisadora traz à tona os cinco tipos de leitores de imagens ${ }^{2}$, conforme os estágios de compreensão em que se encontram. Seu estudo é voltado para os níveis de apreensão dos sentidos das obras de arte, logo, em virtude das idiossincrasias desta pesquisa, tivemos a necessidade de adaptá-los (Tabela 1).

Tabela 1 - Tipos de leitores de imagens em museus de História Natural

\begin{tabular}{|c|c|c|c|c|}
\hline Narrativo & Construtivo & Classificativo & Interpretativo & Re-criativo \\
\hline $\begin{array}{l}\text { Tenta explicar o } \\
\text { que o acervo } \\
\text { significa, não } \\
\text { mantém muito } \\
\text { contato com os } \\
\text { conhecimentos } \\
\text { em História } \\
\text { Natural, porém, } \\
\text { impressiona-se } \\
\text { facilmente com o } \\
\text { tema. Narrador de } \\
\text { histórias. }\end{array}$ & $\begin{array}{l}\text { Questiona-se } \\
\text { sobre como os } \\
\text { aparatos, } \\
\text { dioramas ou } \\
\text { reconstituições } \\
\text { foram feitos. Está } \\
\text { interessado nas } \\
\text { propriedades } \\
\text { formais, } \\
\text { comentando se } \\
\text { os trabalhos } \\
\text { foram bem feitos } \\
\text { ou não. }\end{array}$ & $\begin{array}{l}\text { Leitor- } \\
\text { diagnóstico: está } \\
\text { preocupado em } \\
\text { entender o } \\
\text { contexto formal } \\
\text { do acervo em } \\
\text { consonância com } \\
\text { informações da } \\
\text { área de História } \\
\text { Natural, tentando } \\
\text { classificá-lo } \\
\text { corretamente. }\end{array}$ & $\begin{array}{l}\text { Demonstra uma } \\
\text { aproximação mais } \\
\text { emocional às } \\
\text { questões } \\
\text { estéticas das } \\
\text { imagens } \\
\text { apresentadas na } \\
\text { exposição, } \\
\text { classificando } \\
\text { corretamente o } \\
\text { acervo, num } \\
\text { encontro de } \\
\text { grande carga } \\
\text { afetiva. }\end{array}$ & $\begin{array}{l}\text { Analisa e } \\
\text { interpreta o } \\
\text { acervo em vários } \\
\text { níveis (como, o } \\
\text { que, quem, por } \\
\text { que e quando do } \\
\text { acervo). }\end{array}$ \\
\hline
\end{tabular}

Fonte: Adaptada a partir do esquema de Abigail Housen, citado por Carvalho Neta (2005).

Cinco estudantes comportaram-se como leitores narrativos quanto à compreensão estética do acervo, o que pode ser analisado a partir de seus comentários a respeito da visita ao CPHNAMA. Vejamos algumas das colocações dos licenciandos:

\begin{abstract}
"As samambaias tinham cinco metros de altura e continham um tronco um pouco grosso e se fossilizaram devido ao ambiente" (B8).

"Observei que o número de animais que viviam naquele período é muito maior do que imaginava. A distribuição da vegetação era diferente da de hoje, assim como forma e diversidade da mesma. Observei que o tamanho dos bichos é bem maior do que imaginava" (B12).
\end{abstract}

\footnotetext{
${ }^{2}$ A autora indica o trabalho de Abigail Housen, intitulado The eye of the beholder: measuring aesthetic development (1983), que classifica os leitores de imagens com base nos estágios de compreensão em que se encontram. Para maiores detalhes, ver Carvalho Neta (2005). Em virtude dos contornos próprios assumidos por este trabalho, algumas adaptações foram realizadas. A título de comparação, as características consideradas para leitores de obras de arte podem ser consultadas.
} 
B3 demonstrou preocupação com as propriedades formais dos materiais fósseis e a construção dos demais aparatos que compõem o acervo, aproximandose do perfil de leitora construtiva: "Pude conhecer os fósseis de animais encontrados aqui no Maranhão, observar as diversas formas e as formas das escamas [...] são vários os minerais envolvidos na fossilização, sendo que a sílica está mais envolvida nos fósseis encontrados no solo".

No nível de compreensão estética seguinte, em que o visitante busca classificar o acervo historicamente, conforme a apresentação de suas propriedades formais, três alunos demonstraram este tipo de leitura-diagnóstica. O relato apresentado expõe estas características: "Os locais onde os fósseis são encontrados, suas formas ou tipo de fossilização, como identificar o habitat através da forma, as dimensões dos animais, a diversidade dos estudos" (B5).

Para duas licenciandas, além da classificação correta do acervo, a visita apresentou um caráter emocional em função da experiência vivida e dos conhecimentos aprendidos, assim, realizaram uma leitura interpretativa do que foi exposto. A seguir apresentamos um trecho que revela esse nível de compreensão estética:

"Primeiro, levamos em consideração o desejo do homem de conhecer e se dedicar a entender o seu passado. Fica mais fácil entender e compreender as eras passadas e os seres que pertenciam a cada uma; compreender, de fato, a importância da fossilização para os estudos de Paleontologia" (B10).

Apenas B1 demonstrou conhecimento do acervo em vários níveis, cuja descrição de sua fala apresentada na sequência, aponta para a leitura re-criativa do acervo e da experiência adquirida na visita ao museu de História Natural:

\begin{abstract}
"A visita ao museu deu um maior aprofundamento no que já conhecia sobre vertebrados, trazendo a evolução, principalmente dos peixes e répteis. $A$ explicação do monitor nos resgatou os prováveis ancestrais dos peixes modernos, como era o ambiente no período do aparecimento e apogeu dos dinossauros. Também foi interessante quando o monitor nos mostrou a imagem que sugere a separação dos continentes. Além disso, pudemos confirmar que esses animais e plantas existiam, pois lá existiam fósseis e réplicas que confirmam os processos evolutivos desses grupos". (B1)
\end{abstract}

Foi constatado que a maioria dos alunos apresentou perfil de leitor narrativo, localizado no primeiro nível de compreensão estética, o que denota pouco contato com oportunidades de apreciação e aprimoramento da compreensão estética do 
acervo de um museu. Este tipo de atividade, se mais impulsionado e adequadamente planejado, pode contribuir para a formação de licenciandos que possam apresentar características de um leitor re-criativo, ou seja, com capacidade para interpretar e compreender o acervo em vários níveis. Os licenciados com este nível de aprofundamento e conhecimento estético possuirão o perfil esperado para a realização de atividades complementares relevantes de ensino-aprendizagem de Ciências e Biologia em seus trabalhos como professores, no ambiente escolar. Ademais, poderão contribuir no direcionamento do olhar de seus alunos para a compreensão dos acervos em vários níveis de leitura. Nesse sentido, os formadores de professores, no âmbito das licenciaturas, precisam incentivar e reconhecer a relevância destas atividades e o desenvolvimento deste perfil de leitores re-criativos.

Além de favorecer o desenvolvimento dos professores e alunos leitores de imagens (e constantes aprendizes) dos conhecimentos em Biologia, tais diagnósticos também podem contribuir para o próprio aprimoramento dos museus de ciência, auxiliando os profissionais envolvidos na concepção de exposições a planejar espaços mais adequados ao que seus públicos ensejam. Inseridos nesta perspectiva, os próprios planejadores e mediadores dos museus podem também estimular o seu público a ampliar os níveis de compreensão estética e leitura das obras do acervo, bem como identificar a construção de situações/propostas de ensino-aprendizagem que permitam aos docentes e professores em formação perceberem a importância destas atividades para a sua atuação no ambiente escolar e em articulação com os espaços não formais de educação.

\subsection{IMPORTÂNCIA CONCEDIDA AOS MUSEUS DE CIÊNCIA ENQUANTO ESPAÇO DE FORMAÇÃO DOCENTE}

Antes de adentrarem no museu de ciência para vivenciarem a aprendizagem possibilitada pelo conhecimento do acervo, questionamos os estudantes sobre a importância dos museus de ciência para a formação de professores de Ciências/Biologia. As respostas fornecidas revelaram a crença na possibilidade de aperfeiçoamento dos professores e melhoria do trabalho docente, maior aprendizado 
na área de História Natural, além da oportunidade de uma aula diferente das habituais.

Após a realização da visita, inquirimos novamente os estudantes sobre a importância dos museus para a formação docente, no intuito de averiguar, em seus discursos, os posicionamentos pertinentes a este aspecto. Os licenciandos consideraram o ambiente museal, muitos fazendo referência a espaços como o CPHNAMA, como local de grande valia para o professor destas disciplinas, no sentido de aproximar mais os alunos da prática (em oposição clara às "aulas teóricas"). As respostas fornecidas, que foram compiladas em função de semelhanças e podem ser vistas a seguir (Tabela 2), enfatizaram o ensinoaprendizagem em sala de aula, propostas didáticas para as disciplinas e a exposição de materiais fósseis e demais reconstituições, que podem servir de auxílio à compreensão dos períodos geológicos.

Tabela 2 - Discursos sobre a importância dos museus de ciência para os professores de Ciências/Biologia.

\begin{tabular}{|c|c|c|}
\hline Aproximar o aluno da prática & Dinamizar o aprendizado & $\begin{array}{r}\text { Ensinar a e } \\
\text { seres }\end{array}$ \\
\hline $\begin{array}{l}\text { “[...] Com os novos rumos que } \\
\text { a Educação vem tomando não } \\
\text { dá mais para ficarmos } \\
\text { confinados somente em salas } \\
\text { de aula e laboratórios. É } \\
\text { preciso aproximar o aluno mais } \\
\text { da prática da observação e o } \\
\text { museu é muito importante, pois } \\
\text { confirma e instiga os } \\
\text { estudantes a refletirem sobre } \\
\text { determinado assunto" (B1). } \\
\text { "[...] Acredito que é uma } \\
\text { maneira prática de completar a } \\
\text { teoria dada em sala de aula"” } \\
\text { (B6). }\end{array}$ & $\begin{array}{l}\text { "Para dinamizar o aprendizado" } \\
\text { (B2). } \\
\text { "Une a teoria à prática: a } \\
\text { primeira torna-se mais didática, } \\
\text { mais interdisciplinar [...]" (B9). } \\
\text { "[...] proporciona, na prática, o } \\
\text { que às vezes fica difícil } \\
\text { contextualizar (...) Às vezes, os } \\
\text { livros não fornecem total base } \\
\text { para o desenrolar do } \\
\text { pensamento, aí entra o papel } \\
\text { das práticas e aulas de campo } \\
\text { para fazerem uma maior } \\
\text { integracão" (B11). }\end{array}$ & $\begin{array}{l}\text { "[...] Ajuda o professor para } \\
\text { uma melhor explicação do } \\
\text { assunto. É importante também } \\
\text { para os alunos, que aprendem } \\
\text { melhor visualizando os animais } \\
\text { extintos" (B3). } \\
\text { "O museu consegue dar uma } \\
\text { visualização melhor da teoria } \\
\text { abordada em sala de aula, } \\
\text { porque é bem difícil que o } \\
\text { aluno aprenda sobre animais e } \\
\text { plantas que já foram extintos, } \\
\text { sem ter uma visualização [...]" } \\
\text { (B4). }\end{array}$ \\
\hline
\end{tabular}

Fonte: Elaborado a partir de trechos dos questionários respondidos pelos licenciandos após a visita ao CPHNAMA.

É possível depreender, a partir das considerações dos licenciandos, a relevância das atividades realizadas em museus de ciência e de que modo eles pretendem incorporar estas propostas em suas atuações como docentes. Esta constatação coaduna com a perspectiva de Abib (2012), que chama atenção para a 
necessidade de enxergarmos os museus não apenas como espaços de divulgação científica, mas como locais que possam oferecer as possibilidades de autoformação e de formação continuada, nas quais o professor seja capaz de refletir sobre as implicações destes espaços em novas percepções sobre as suas próprias práticas docentes.

Ovigli, Freitas e Caluzi (2010) acrescentam que, enquanto instância educativa, os museus de ciência também contribuem para a formação docente, no que se refere ao contato com as ações de alfabetização científica que ocorrem nesses espaços. Além disso, como ressaltam Gomes e Cazelli (2014), a formação do educador precisa ser compreendida de forma mais ampla, nesse sentido, devem ser incentivadas e valorizadas as oportunidades de estreitar as relações entre os conhecimentos construídos nos espaços formais e não formais de educação.

Os museus, portanto, representam uma possibilidade de enriquecer os processos de formação docente, despertando os licenciandos sobre a importância desses espaços e sobre as múltiplas formas de utilização de seus recursos como incremento às suas práticas pedagógicas. Estes ambientes não formais de educação proporcionam a ampliação do espectro de atuação desses profissionais em formação (OVIGLI, 2011). Diante destes pressupostos e da necessidade de ampliação destes tipos de atividades e de reflexão acadêmica sobre as produções científicas da área, tornam-se relevantes as informações aqui reunidas a respeito de professores em constituição, em relação à inserção do ambiente museal em suas instâncias de formação.

\section{CONSIDERAÇÕES FINAIS}

No que concerne à importância concedida aos museus enquanto espaço de formação docente, os discursos dos licenciandos reverberam contribuições que estes ambientes podem oferecer: aprender mais sobre História Natural e Evolutiva dos seres vivos; complementar o que é aprendido no Curso de Ciências Biológicas; enriquecer os conhecimentos desenvolvidos em sala de aula; e realizar aulas diferentes. 
Para os níveis de compreensão estética, a maioria das apropriações dos estudantes apresentou-se mais próxima ao primeiro tipo de leitor, o narrativo, sendo apenas uma estudante re-criativa, interpretando o acervo em vários níveis. Isso demonstra falta de prática no treino do olhar estético para a leitura de imagens, atestando a pouca frequência e o distanciamento dos licenciandos deste tipo de atividade, que deveria ser mais comum em seu processo formativo.

É crucial aos estudantes e professores da área de Ciências Biológicas não apenas vivenciarem experiências museais, mas participarem de outras atividades que envolvam a divulgação da ciência. É fundamental também ouvir, dar oportunidade de voz aos licenciandos, a fim de reconhecer suas motivações, realidades de formação, expectativas e compromissos com a docência. Neste ponto, há a possibilidade de os próprios licenciandos, bem como dos demais envolvidos em seu processo de constituição, enquanto professores, reavaliarem seus discursos, práticas e perspectivas de formação docente.

Portanto, diante dos resultados encontrados por este trabalho, cabe ressaltar as transformações no perfil docente que o estreitamento entre a educação formal universitária e a educação não formal dos museus de ciência podem representar para a formação dos licenciandos em Ciências Biológicas e para os educadores de forma geral. Os museus de ciência possibilitam: o aprimoramento dos conhecimentos biológicos, oportunidades de alfabetização científica dos professores em formação e maior contato com atividades de divulgação científica; melhorias no processo de ensino-aprendizagem nas universidades e estreitamento das relações entre estas instituições e os museus, fomentando também o estabelecimento de parcerias acadêmicas; ampliar o nível de aprofundamento para compreensão estética do acervo e leitura das obras de arte da exposição; maior reflexão sobre a importância destes tipos de atividades e sobre as suas próprias práticas docentes; formação continuada e autoformação; reconhecer uma gama de oportunidades de utilização desses espaços como recursos didáticos complementares ao seus trabalhos como professores no âmbito escolar; e, por fim, corroborar para a formação de novos pesquisadores, interessados em investigar questões científicas relacionadas a esta área. 


\section{CARLOS ERICK BRITO DE SOUSA}

Mestre em Educação. Professor Assistente do Departamento de Biologia da Universidade Federal do Maranhão (UFMA).

\section{RAIMUNDA NONATA FORTES CARVALHO NETA}

Doutora em Biotecnologia. Professora da Universidade Estadual do Maranhão (UEMA) e coordenadora do Mestrado em Recursos Aquáticos e Pesca da UEMA.

\section{REFERÊNCIAS}

ABIB, M. L. V. S. et al. Os espaços não formais e sua relação com a formação de professores no contexto brasileiro. In: Anais XVI Encontro Nacional de Didática e Práticas de Ensino - ENDIPE. Campinas: ENDIPE, 2012. p. 1-12.

ALVES, S. C. Arte: uma experiência estética em museu. In: Anais $30^{a}$ Reunião Anual da ANPED. Caxambu: ANPED, 2007. p. 1-15.

CARVALHO NETA, R. N. F. O professor de Arte e a formação do olhar. In:

CARVALHO NETA, R. N. F. (Org.). Arte Maranhense: produção \& ensino. São Luís: R. Fortes, 2005. p. 260-266.

CAZELLI, S. et al. Tendências pedagógicas das exposições de um museu de ciência. In: Anais II Encontro Nacional de Pesquisa em Educação em Ciências ENPEC. Valinhos: ENPEC, 1999. p. 1-12.

COUTINHO-SILVA, R. et al. Interação Museu de Ciências-Universidade:

contribuições para o ensino não-formal de Ciências. Ciência e Cultura, v. 57, n. 4, p. 24-25, 2005.

DELIZOICOV, D.; ANGOTTI, J. A.; PERNAMBUCO, M. M. Ensino de Ciências: fundamentos e métodos. São Paulo: Cortez, 2009. (Coleção Docência em Formação).

GOMES, I.; CAZELLI, S. Formação de mediadores em museus de ciência: diálogos entre a educação formal e não formal. Revista Educação Online, n. 16, p. 1-22, maio-ago., 2014.

JACOBUCCI, D. F. C. et al. A formação continuada de Professores em centros e museus de ciências no Brasil. In: Anais 30ª Reunião Anual da ANPED. Caxambu: ANPED, 2007. p. 1-17.

MARANDINO, M. Educação em museus de História Natural: possibilidades e desafios de um programa de pesquisa. Enseñanza de las Ciencias, n. extra, VII Congreso, 2005, p. 1-4. 
; MARTINS, L. C. Um dia no museu: a ação educativa vista através de uma visita. In: MASSARANI, L. (Org.). O pequeno cientista amador: a divulgação científica e o público infantil. Rio de Janeiro: UFRJ/Fiocruz, 2005. (Série Terra Incógnita). p. 77-84.

MASSARANI, L.; MOREIRA, I. C. Aspectos históricos da divulgação científica no Brasil. In: MASSARANI, L.; MOREIRA, I. C.; BRITO, F. (Org.). Ciência e Público: caminhos da divulgação científica no Brasil. Rio de Janeiro: Casa da Ciência/UFRJ, 2002. p. 43-64.

MEGID NETO, J.; FAHL, D. D. Marcas do ensino escolar de Ciências presentes em museus e centros de Ciências. In: Anais XVI Simpósio Nacional de Ensino de Física - SNEF. Rio de Janeiro: SNEF, 2005. p. 1-4.

OVIGLI, D. F. B. Prática de Ensino de Ciências: o museu como espaço formativo. Rev. Ensaio, v. 13, n. 3, set-dez, 2011, p. 133-149.

OVIGLI, D.F.B; FREITAS, D.; CALUZI, J. J. Quando os museus de ciências tornamse espaços de formação docente. In: PIROLA, N. A. (Org.). Ensino de Ciências e Matemática, IV: temas de investigação. São Paulo: Cultura Acadêmica, 2010. p. 95114.

SILVA, V. C. et al. Museu Interdisciplinar de Ciências da Unipar (MIC): relato das atividades desenvolvidas de 2003-2005. Arquivos do Mudi, v. 11, n. 1, 2007, p. 1320.

STUDART, D. C. Aparatos interativos e o público infantil em museus: características e abordagens. In: MASSARANI, L. (Org.). O pequeno cientista amador: a divulgação científica e o público infantil. Rio de Janeiro: UFRJ/Fiocruz, 2005. (Série Terra Incógnita). p. 65-76.

SHWENK, B.; MARTELETO, R. M. Ciência Móvel: a mediação informacional nas exposições em um museu itinerante. In: Anais XII Reunião Bienal de la Red POP. Campinas: Red POP, 2011. p. 1-9.

VALENTE, M. E. A. Interseções Necessárias: história, museologia e museus de ciências e tecnologia. Museologia \& Interdisciplinaridade, v. 3, n. 5, maio-jun, 2014, p. 37-53. 